\title{
Interdisciplinary Framework: A Building Information Modeling Using Structural Equation Analysis in Lean Construction Project Management
}

\author{
Dante SILVA $^{\mathrm{a}, 1}$, Kevin Lawrence DE JESUS ${ }^{\mathrm{a}}$, Bernard VILLAVERDE ${ }^{\mathrm{a}}$, \\ Andrea Isabelle ENCISO ${ }^{a}$, Amanda Nicole MECIJA a, Justin Owen MENDOZA ${ }^{\text {a }}$

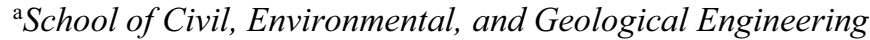 \\ Mapúa University, Manila, Philippines
}

\begin{abstract}
The construction process and construction management are highly reliant on the interaction between the triple constraints of project management of quality: scope, time, and cost. The industry has incorporated certain principles and technology, such as lean-based construction principles and Building Information Modeling (BIM), to maximize the time, quality, and cost-efficiency of various construction projects. Analysis and assessment of the factors and functionalities are needed to show their synergic relationships and determine their significant impact on the construction project using Structural Equation Modeling (SEM). To gather information, a survey was conducted on the different construction companies in the Philippines. The results generated a model interrelating the triple constraints of project management and how they are affected by incorporating BIM and lean construction principles. The models created established a significant relationship towards all the tripe constraints considering both individual and combined functionalities and factors. An interdisciplinary framework incorporating both BIM and lean principles is conformed to optimize construction stages based on the triple constraints of project management.
\end{abstract}

Keywords. Building Information Modeling (BIM), lean construction principles, triple constraints of project management, Structural Equation Modeling (SEM), interdisciplinary framework

\section{Introduction}

The construction industry has continually progressed from traditional to more advanced methods to achieve more high-quality outcomes for a shorter time and with fewer expenditures. With the increasing complexity of projects as time goes by, construction projects encounter a wide range of challenges that can either slow down the construction process or incur more costs such as natural calamities, public health emergencies, and countless unforeseen events. Construction management has different correlated parameters needed to consider, including the time, cost, and scope in preparation for the flow of the construction regardless of circumstances. Communication is an important factor in improving the productivity on site, therefore reducing problems. The

\footnotetext{
${ }^{1}$ Corresponding Author: Dante L. Silva, School of Civil, Environmental, and Geological Engineering, Mapúa University, Manila, Philippines, E-mail: dantesilva2000@yahoo.com
} 
interdisciplinary factors associated with the issues in construction affects the progress of the external and internal site. [1]. Sustainability strategies take place to offer efficient and effective performances in the industry [2]. Two methodologies were implied to show the relationship of the triple constraints to the flow and process of the construction.

Building Information Modeling (BIM) is characterized as a digital model that imposes collaboration among project stakeholders [3]. The concept of BIM takes place through a life cycle of digital information, starting from conceptual design up to demolition. Its widespread use makes a significant effort in advancing the software and tools available in the market today [4,5]. On the other hand, lean construction was introduced to the construction industry from the principles being applied in the production industry from the Toyota Production System [6]. It provides continuous improvement in the industry by minimizing wastes to improve efficiency. These methods evolved throughout the years and are considered effective techniques applied for a strategic approach towards the construction sector [7].

The research is intended to formulate an interdisciplinary framework integrating both Building Information Modeling (BIM) and Lean Construction principles concerning the triple constraints of project management in the Philippine construction industry using Structural Equation Modeling (SEM). Provided their impact on output efficiency, the factors and functionalities of both BIM and Lean construction are integrated to determine the relationship of each parameter formed that affects the triple constraints throughout the different stages of construction projects.

\section{Methodology}

The methodology of the study is divided into five different phases. It involved researching online databases for preliminary research/information regarding the potential risks throughout the construction project phases. The designing of the survey questionnaire patterned from the existing information gathered on the related literature and studies. Cronbach's alpha (CA) was conducted to validate the survey questionnaire from the collected data from key construction companies in the Philippines. The researchers analyzed each component and identified the parameters needed to be focused on regarding the manifestation of Building Information Modeling (BIM) and lean construction principles alongside the triple constraints of project management: time, scope, and cost. The data being interpreted was evaluated to see its interaction through Structural Equation Modeling Analysis with measurement and structural model. The researchers defined the measurement model by utilizing Confirmatory Factor Analysis (CFA) procedures. Methods of factor computations were performed to alleviate the relationship of the variable with programming software, SPSS AMOS and Statistics. a complete measurement model was produced to emphasize the specified testing of hypotheses. Lastly, to finalize the full structured framework, the data collected from the measurement model is used for model fit assessment and path assessment and estimating squared multiple correlations. It is being interpreted to finally answer the seven (7) hypotheses set in this study in relation to the individual and combined triple constraints including time, cost, scope, time-scope, scope-cost, cost-time, and time-cost-scope and how it affects to the interaction of BIM and lean. 


\section{Data and Discussion}

\subsection{Preliminary Research on the Risks and Issues Encountered on Construction Projects}

The risks and problems encountered in construction are classified based on the people, process, and technology which organized the ideologies for streamlined flow. One common problem in the construction industry is a delay that may be caused by several factors including, but not limited to procurement, unforeseen events, low productivity rates, and change orders. These problems are encountered due to the lack of either time, budget, or scope.

\subsection{Designing the Survey Questionnaire}

The Cronbach alpha generated from the survey questionnaire was sufficient to satisfy the given conditions possessing acceptable values of 0.7 and above [8]. The reliability of the individual model with 24 observed factors (Cronbach $\alpha=0.77$ ) is higher than the combined model with 32 observed factors (Cronbach $\alpha=0.72$ ). Considering the whole assessment for both models supported, it was verified with a relatively good value of 0.83 .

\subsection{Collection, Analysis, and Cleaning of Data}

The researchers created hypothetical models that conceptualized the hypothesis tested in the study from the individual and combined factors. The triple constraints for both models were represented by ellipse or circle. Observed variables from the survey questionnaires were presented by rectangles. Single-head arrows were connected, representing the impact on another latent variable to the observed factors. Double-head arrows were used to show the covariances of the combined constraints. Errors of measurements are correlatedly associated with each observed variable, yet these measures are uncorrelated. Values and calculations needed for the analysis were generated using SPSS AMOS and Statistics.

\subsection{Evaluation through Confirmatory Factor Analysis}

In the analysis, considering the triple constraints of project management, the individual and combined factors satisfy the given 0.7 or higher factor loading criteria. Thus, all these factors show a positive and significant effect on the measured variables, supporting all hypotheses stated in the research study. Take note that the factor loadings for the latent variables in the prediction of the observed factors are significantly different from zero at the 0.001 level or two-tailed.

The researchers associated the variables by getting their Average Variance Extracted (AVE) and Composite Reliability (CR). The AVE measured the amount of variance that was implied based on the measurement errors. The CR is defined as the measurement of the internal consistency in scaling items. The ideal value of the Average Variance Extracted should be greater than 0.50 , and the Composite Reliability should fall in the range of 0.70 or higher. [9]. The calculated AVE of all variables is found to be greater than 0.5 for both structured models, which indicates that all questions reflect the variables 
indicated in the study. Moreover, the Composite Reliability of the three latent variables has a value greater than 0.7 . This high value of CR indicates a high consistency among all the observed factors of the questionnaire. Provided both ideal values of the AVE and $\mathrm{CR}$ are achieved, the validity of the latent variables is established, and the model has good reliability.

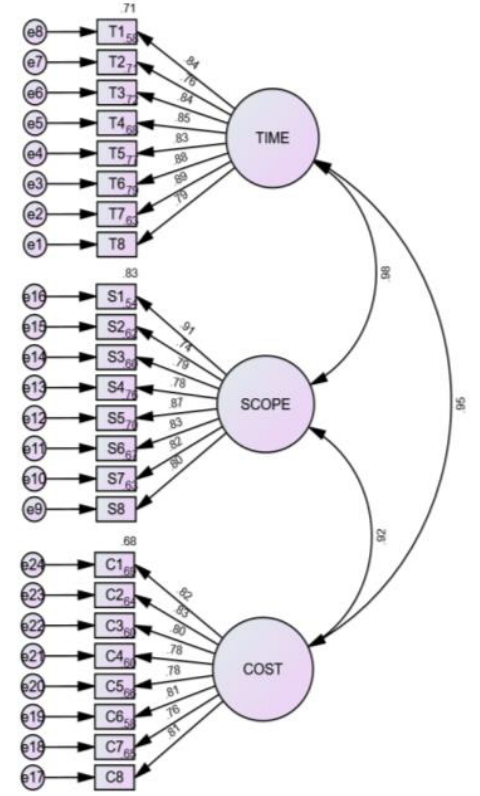

(a)

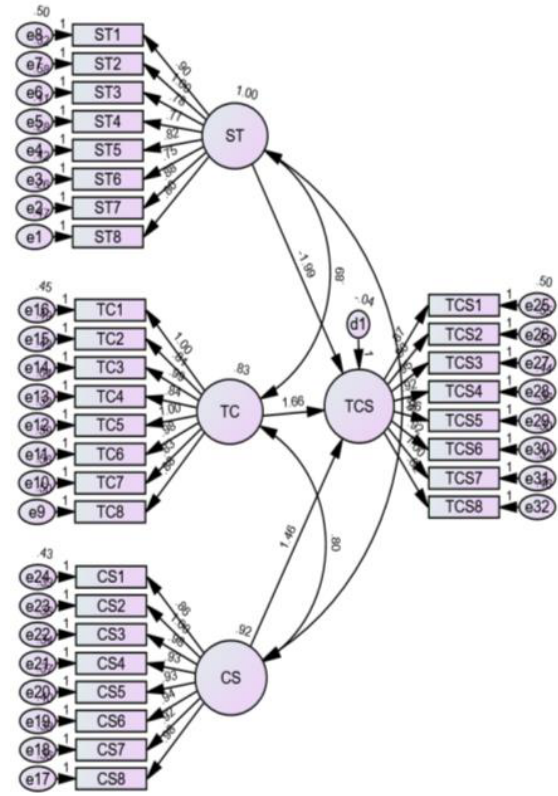

(b)

Figure 1. Structural Model of (a) Individual Functionalities and Factors and (b) Combined Functionalities and Factors

Figure 1 shows the structural model for both the individual and combined functionalities, showing their factor loadings against one another. The factor loadings describe the correlation between two variables within the structural model with ideal values of 0.7 or higher. All observed factors that were considered for the model have significant relationships for the study since all values obtained were above the ideal value of 0.7. Overall, considering the factor loadings generated using the SPSS AMOS software, time and scope has the most significant relationship among all the variables, with 0.98 factor loading. Next is scope and time with 0.95 , followed by cost and scope with 0.92 as their factor loadings.

\subsection{Finalization of the Structured Frameworks}

The researchers determined the discriminant validity through squared multiple correlations to assess the low correlation among the variables and identify distinctions among factors. To establish the discriminant validity, the value of the squared multiple correlations should be lower than the average variance extracted. For the discriminant validity for the individual functionalities, the variable of cost, the observed factors $\mathrm{C} 1$, $\mathrm{C} 2$, and $\mathrm{C} 6$ were not established. This is the same with the observed factors of S1, S5, S6, and S7 for the variable scope, and T4, T6, and T8. For the discriminant validity of the combined functionalities, it has two (2) latent variables with observed variables that 
are not established: cost and scope (CS) and scope and time (ST). The majority of the observed variables for cost and scope were not established, apart from CS1. Half of the observed variables are not established in the latent variable of scope and time, namely ST1, ST2, ST5, and ST7. All observed variables under time and cost (TC) and time, cost, and scope (TCS) have a value of AVE higher than the squared correlation, which indicates an established discriminant validity. This information indicates that although the convergent validity is established and the observed factors significantly represent the latent factors, the observed ones not established correlate better with other latent variables than its parent variable.

Goodness-of-fit tests ensured that the data that were collected are normally distributed with eight (8) fit indices [10]. In both models, the fit indices generated using the data of this study showed acceptable values which indicates that the model can represent the entire population due to its normality.

Table 1. Goodness-Of-Fit Testing for Individual and Combined Models

\begin{tabular}{cccc}
\hline Fit Indices & \multicolumn{2}{c}{ Parameter Estimates } \\
Combividual & $\begin{array}{c}\text { Recommended } \\
\text { Values }\end{array}$ \\
\hline Chi-square $(\chi 2)$ P-value & $\begin{array}{c}\text { Non- } \\
\text { significant } \\
(\mathrm{p}=0.069)\end{array}$ & $\begin{array}{c}\text { Non-Significant } \\
(\mathrm{p}=0.053)\end{array}$ & $\geq 0.05$ \\
Normed Chi-Square $(\chi 2 / \mathrm{df})$ & 1.148 & 1.121 & $>3.00$ \\
Incremental Fit Index (IFI) & 0.988 & 0.986 & $\geq 0.90$ \\
Tucker-Lewis Index (TLI) & 0.983 & 0.981 & $\geq 0.90$ \\
Comparative Fit Index (CFI) & 0.987 & 0.986 & $\geq 0.90$ \\
Root Mean Square Error of Approximation (RMSEA) & 0.039 & 0.035 & $\leq 0.05$ \\
Goodness of Fit Index (GFI) & 0.851 & 0.821 & $\geq 0.80$ \\
Adjusted Goodness of Fit Index (AGFI) & 0.787 & 0.749 & $\geq 0.90$ \\
\hline
\end{tabular}

The interdisciplinary framework illustrated in Figure 2 summarizes the result of this research. Each latent variable were linked to the different stages of construction wherein these variables are related to. Consequently, each of the factor associated with divisions including the people, process, and technology. The initial roster of 56 latent variables were reduced to 35 , eliminating those which are not established when the discriminant validly was tested. The observed variables included in the framework created was examined based on the assessed outcomes from their factor loadings. Out of the initial eight latent variables identified, only four was established with the scope, five with time, five with cost, four with scope-time, one with cost-scope, eight with time-cost, and eight with all three time-cost-scope. All the denied variables indicated that the following information does not established relationship towards the underlying data in connection to workflow reliability in construction [11]. Through this analysis, it can be determined that BIM and lean has its positive influence and correlations towards the triple constraints of project management showing that all the hypothesis satisfied and confirmed in the study. Furthermore, the results of varying path coefficients of SEM analysis suggested that the triple constraints have its great impact towards the project, supporting the claims on streamlined networks of communication, the dynamics and flexibility of triple constraints in quality project delivery, and optimized waste reduction [12,13]. 
BIM-Lean Interdisciplinary Framework

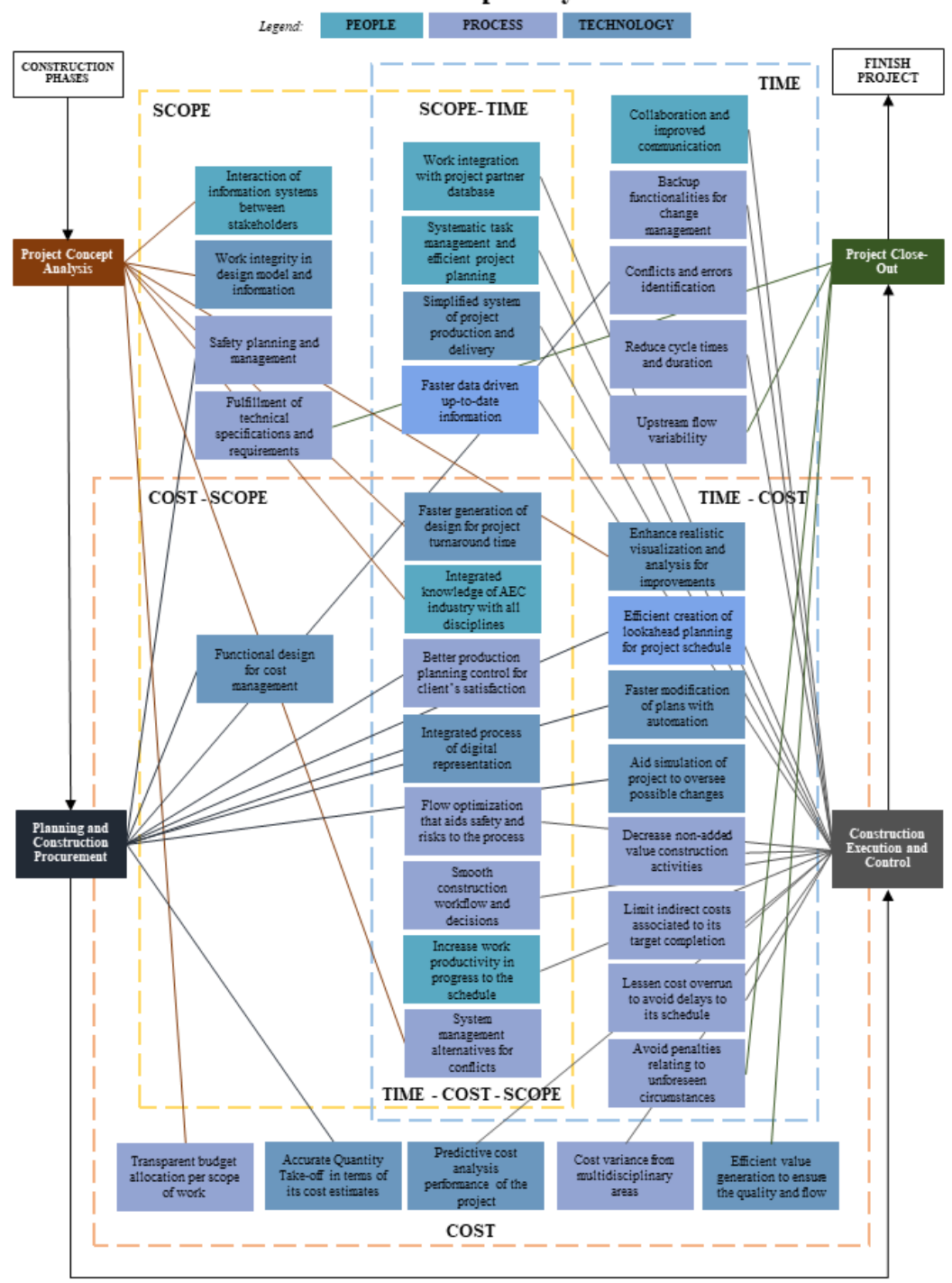

Figure 2. BIM-Lean Interdisciplinary Framework

\section{Conclusion}

The paper identified and tested the observed variables in relation to the factors and functionalities through Structural Equation Modeling Analysis. The research output of the structural model pointed out that usage of the Building Information Modeling and incorporation of Lean construction principles can result in the holistic improvement of the project scope, time efficiency, and a reduced overall cost to the project that can be a 
basis to reinvent the risks and challenges in the construction industry. The application of BIM and lean significantly affects the construction project, starting from the project concept analysis up to the project closeout as the number of problems that arise throughout the project is significantly minimized. All the triple constraints of project management were interrelated with their individual and combined functionalities and factors in such way that it influences one another most especially in construction projects.

The interrelated factors with its focused approach are helpful towards the performance, reliability, and operations of the project. The main stakeholders such as the engineers, architects, contractors, and designers are influential professionals associated with integrating BIM and lean principles in terms of triple constraints as their collaborative efforts make significant relations to other stakeholders and clients involved in the project. Lastly, the effects of innovative technology such as birth of advanced software and hardware affect the triple constraints as well as possible risks and issues throughout the project duration.

\section{References}

[1] Silva DL, Macariola RN. Coping with the Information Age: Development of a Data Flow Diagram-Based Knowledge Management System for Mitigating Delays for Construction. OP Conf. Series: Materials Science and Engineering. 2019;652,12070.

[2] Silva DL, Villaverde B, De Jesus KLM, Marcial Jr. L. Design Initiative Implementation Framework: A Model Integrating Kolmogorov-Smirnov in Sustainable Practices for Triple-Bottom-Line Principles in Construction Industry. 2020;8(4):1.

[3] Schimanski CP, Marcher C, Monizza GP, Matt DT. The last planner system and building information modeling in construction execution: From an integrative review to a conceptual model for integration. Applied Sciences (Switzerland). 2020;10(3).

[4] Borrmann A, König M, Koch C, Beetz J. Building Information Modeling: Technology Foundations and Industry Practice: Springer. 2018; p. 584.

[5] Rodriguez LV, Bagcal OR, Baccay MA, Barbier BM. Adoption of Building Information Modeling (BIM) in the Philippines' AEC Industry: Prospects, Issues, and Challenges. ResearchGate. 2019 July; 9(2).

[6] Kagioglou M, Koskela L, Tzortzopoulos P. Lean Construction Core Concepts and New Frontiers; 2020. 460

[7] Parfenova E, Avilova ZN, Ganzha AN. Lean construction - an effective management system in the construction industry. IOP Conf Ser Mater Sci Eng. 2020; 945(1).

[8] Taber KS. The Use of Cronbach's Alpha When Developing and Reporting Research Instruments in Science Education. Res Sci Educ. 2017 June; 48:1273-1296.

[9] Ab Hamid MR, Sami W, Mohmad Sidek MH. Discriminant Validity Assessment: Use of Fornell \& Larcker criterion versus HTMT Criterion. J Phys Conf Ser. 2017; 890(1): 012163.

[10] Ismail NA, Idris NH, Ramli H, Muhammad Rooshdi RR, Sahamir SR. The relationship between cost estimates reliability and BIM Adoption: Sem analysis. IOP Conf Ser Earth Environ Sci. 2018: 117, 012045.

[11] Zhang L, Chen X, Suo Y. Interrelationships among critical factors of work flow reliability in lean construction. J Constr Eng Manag. 2017 July. 23(5); 621-632.

[12] Antunes R, Gonzalez V. A Production Model for Construction: A Theoretical Framework. Buildings 2015. 2015 Mar; 5(1): 209-228.

[13] Heigermoser D, García de Soto B, Abbott ELS, Chua DKH. BIM-based last planner system tool for improving construction project management. Autom Constr. 2019 May; 104, 246-254. 